\title{
MECHANICAL ALLOYING OF HIGH NITROGEN STAINLESS STEEL POWDERS WITH METAL NITRIDES AND NITROGEN-CONTAINING FERROALLOY AS A NITROGEN SOURCE
}

\author{
Nikolay RAZUMOV, Tagir MAKHMU, Anatoliy POPOVICH, Evgeniy GYULIKHANDANOV, \\ Artem KIM, Alexey SHAMSHURIN
}

\author{
Peter the Great St, Petersburg Polytechnic University, St. Petersburg, Russian Federation, \\ n.razumovonti@onti.spbstu.ru
}

https://doi.org/10.37904/metal.2019.842

\begin{abstract}
$16 \mathrm{Cr}-2 \mathrm{Ni}-\mathrm{Mn}-\mathrm{Mo}-\mathrm{xN}$ (wt\%) stainless steel powders were synthesized by mechanical alloying (MA) of elemental powders, metal nitride (MeN) powders and nitrogen-containing ferroalloy (FeMeN) powders at argon atmosphere. The microstructural and phase evolution of the powders at different times of alloying and microstructure were studied. The X-Ray diffraction (XRD) and Scanning Electron Microscopy (SEM) analysis showed that chemical homogeneity improves with increasing alloying time and decreasing nitrides powder content. The phase composition changes during the MA up to $30 \mathrm{ks}$ processing time showed dissolving of alloying elements and formation of a-phase solid solution for the sample with low nitrogen contents. Samples with high nitrogen contents have a nitrides inclusion, which partially dissolves with increasing processing time.
\end{abstract}

Keywords: High nitrogen stainless steels, mechanical alloying, microstructure, phase evolution

\section{INTRODUCTION}

One of the most important trends in the development of new generation aviation technology is to maximize the ease of components and parts in order to reduce the weight of the aircraft [1]. At the same time, it is necessary to increase the reliability and durability of significant components and parts.

In modern aviation technology, high-strength corrosion-resistant steels are widely used [2,3]. High-strength corrosion-resistant steel used for the manufacture of significant parts must maintain a sufficient level of ductility, toughness, weldability and reduce the cost of production of the material. One of the ways to solve this task is to develop high-strength corrosion-resistant nitrogen-alloyed steels. The addition of nitrogen to steel reduces the need for expensive alloying elements, such as nickel, manganese or molybdenum [4]. The presence of nitrogen in steel as an alloying element in an amount exceeding the equilibrium, leads to the formation of a supersaturated solid solution, by analogy with a supersaturated solid solution of carbon in iron, due to which the material is hardened. In addition, nitrogen reduces the stacking fault energy, which allows increasing the plastic properties of steel along with an increase in strength $[5,6]$.

The possibility of using corrosion-resistant nitrogen-doped steels in additive technologies is of considerable interest. Currently, common methods of obtaining powders for additive technologies do not allow obtaining of powders with superequilibrium nitrogen content. One of the alternative ways to obtain such powders is mechanical alloying followed by spheroidization $[7,8,9]$. Powder high-nitrogen austenitic alloys $\mathrm{Fe}-18 \mathrm{Cr}-8 \mathrm{Ni}$ - 12Mn - xN (wt\%) with nitrogen content of up to $1 \mathrm{wt} \%$ and a nanocrystalline structure of up to $30 \mathrm{~nm}$ have been produced at the St. Petersburg Polytechnic University by mechanical alloying of iron in a nitrogencontaining atmosphere [10].

The aim of the present work was to determine the effect of nitrogen doping method and action of the treatment time on the processes of phase formation and dissolution of alloying elements during mechanical alloying. 


\section{MATERIALS AND METHODS}

The system Fe-16Cr-2.2Ni-0.6Mn-1.1Mo (wt\%) was chosen for research. Nitrogen (gas), nitrogen-containing ferrochrome $(\mathrm{FeCr})$, nitrogen-containing ferromanganese $(\mathrm{FeMn})$, chromium nitride $(\mathrm{Cr} 2 \mathrm{~N})$ and manganese nitride $(\mathrm{Mn} 2 \mathrm{~N})$ were used as the source of nitrogen. Scientific research was carried out on the following compositions:

1) Fe-Cr-Ni-Mn-Mo (nitrogen atmosphere),

2) $\mathrm{Fe}-\mathrm{Cr}_{2} \mathrm{~N}-\mathrm{Ni}-\mathrm{Mn}-\mathrm{Mo}$,

3) $\mathrm{Fe}-\mathrm{Cr}_{2} \mathrm{~N}-\mathrm{Ni}-\mathrm{Mn}_{2} \mathrm{~N}-\mathrm{Mo}$,

4) Fe-Cr-Ni-FeMn-Mo,

5) Fe-FeCr-Ni-Mn-Mo,

6) $\mathrm{Fe}-0.5 \mathrm{Cr}-0.5 \mathrm{Cr}_{2} \mathrm{~N}-\mathrm{Ni}-\mathrm{Mn}-\mathrm{Mo}$,

7) Fe-0.5Cr-0.5FeCr-Ni-Mn-Mo.

Powders of these compositions were synthesized by mechanical alloying (MA) in a laboratory attritor with a grinding chamber capacity of 15 liters. Powders of carbonyl iron (99.0\%), chromium $(99.5 \%)$, electrolytic nickel $(99.9 \%)$, molybdenum $(99.5 \%)$, manganese (98\%), nitrogen-containing ferrochrome, nitrogencontaining ferromanganese, chromium nitride, (99.9\%) and manganese nitride (99.9\%) were used as initial components. The synthesis was carried out with the following parameters: shaft speed of attritor- 600 rpm; grinding balls diameter - $\varnothing 7-10 \mathrm{~mm}$; ball-to-powder mass ratio is $1: 10$; batch weight - $2 \mathrm{~kg}$; alloying time - 5 $30 \mathrm{ks}$, atmosphere - argon, except for composition No. 1 (nitrogen).

The phase composition was investigated by XRD (X-Ray diffraction analysis), using Bruker D8 ADVANCE (Germany) diffractometer in Cu Ka-rays $(\lambda=0.15418 \mathrm{~nm}, \mathrm{U}=40 \mathrm{kV}, \mathrm{I}=40 \mathrm{~mA})$. The processing of the obtained diffraction data was carried out according to the Rietveld method using the Diffrac Plus Topas program. The morphology of the obtained powders, the structure of the sintered samples and the distribution of elements were studied using a scanning electron microscope Mira 3 Tescan with EDX for energy-dispersive X-ray spectroscopy.

\section{RESULTS AND DISCUSSION}

At the initial stages of the MA, the process of dissolving alloying elements is of a general nature for all studied compositions. At the beginning of the MA process, due to severe plastic deformation, particles of the initial powder are flattened, welded together and form a composite. Composite particles after 5-10 ks MA have a characteristic layered structure consisting of various combinations of initial components (Figure 1). A further increase in the duration leads to the homogenization of the composition according to the chemical composition and the interaction between the initial components, aimed at reducing the free energy of the system (Figure 2). XRD results analysis (Figure 3, resp. Figure 3a) showed that $\mathrm{Ni}\left(\mathrm{r}_{\mathrm{a}}=124 \mathrm{pm}\right.$ ) is the first alloying element to dissolve in the iron lattice, then $\mathrm{Mn}\left(\mathrm{r}_{\mathrm{a}}=127 \mathrm{pm}\right), \mathrm{Cr}\left(\mathrm{r}_{\mathrm{a}}=130 \mathrm{pm}\right)$ and $\mathrm{Mo}\left(\mathrm{r}_{\mathrm{a}}=139 \mathrm{pm}\right)$. This is explained by the fact that alloying elements $\mathrm{Ni}, \mathrm{Mn}, \mathrm{Cr}$ form substitutional solid solutions with iron, and nickel has the closest atomic radius to $\mathrm{Fe}-126 \mathrm{pm}$, followed by manganese, chromium and molybdenum, respectively. Alloying elements dissolution leads to a change in the lattice parameter $\alpha-\mathrm{Fe}$ from 0.2866 to $0.2869 \mathrm{~nm}$, depending on the system. Taking into account components ratio sizes in the Fe-Cr-Ni-Mn-Mo system, it can be assumed that in this system the diffusion in MA process is predominantly due to lattice defects.

In the initial Fe-Cr-Ni-Mn-Mo system and in the Fe-Cr-Ni-FeMn-Mo system, where nitrogen-containing ferromanganese was used as the nitrogen source, after $30 \mathrm{ks}$ MA alloying elements are uniformly distributed 
throughout the powders and correspond to the initial chemical composition, the exception is Mo, the radius of the atom which is significantly larger than the other elements of the composition, which significantly complicates its dissolution. Grain size varies from 110 to $15 \mathrm{~nm}$. The similarity of the MA process in these systems is due to the fact that the nitrogen-containing ferromanganese is manganese nitride, an easily decomposable compound, with inclusions of iron and its small amount in the initial mixture.
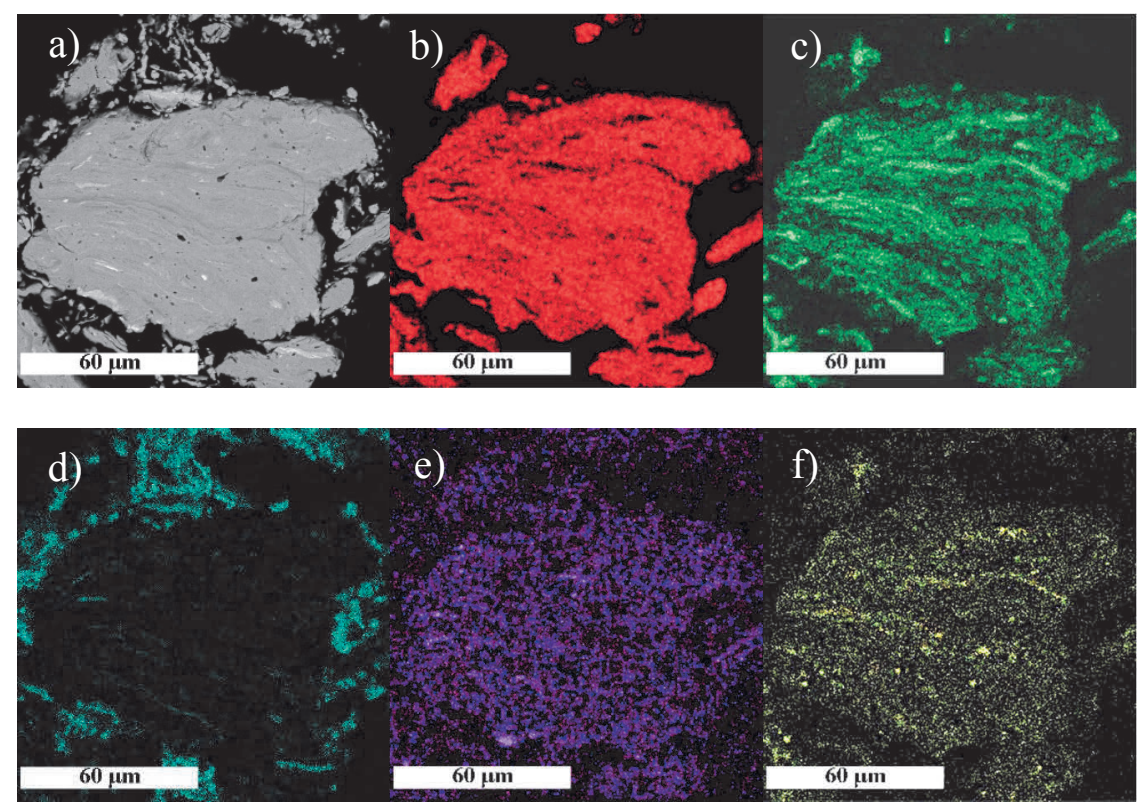

Figure 1 Distribution of components in the Fe-Cr-Ni-Mn-Mo composition after MA for $10 \mathrm{ks}$ : a) general view; b) $\mathrm{Fe}$; c) $\mathrm{Cr}$; d) Ni; e) Mo; f) Mn
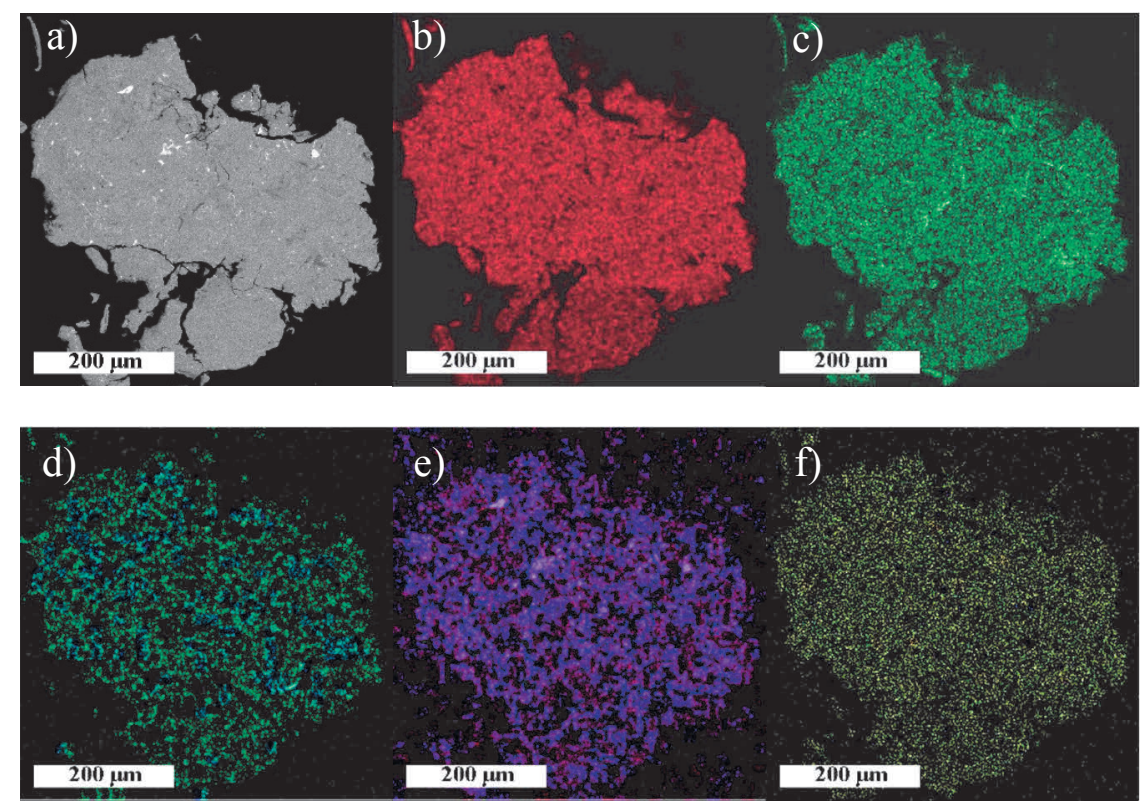

Figure 2 Distribution of components in the Fe-Cr-Ni-Mn-Mo composition after MA for 30 ks: a) general view; b) $\mathrm{Fe}$; c) $\mathrm{Cr}$; d) Ni; e) Mo; f) Mn

In systems with a source of nitrogen in the form of chromium nitride and nitrogen-containing ferrochrome (contains the $\mathrm{CrN}$ phase and some $\mathrm{Cr}_{2} \mathrm{~N}$ ), the dissolution of alloying elements is worse than in the initial composition. Even after $15 \mathrm{ks}$ MA there is heterogeneity in the distribution of alloying elements by volume. 
After $30 \mathrm{ks} \mathrm{MA}$, chromium remains irregularly distributed. It is inside the particles in the form of submicronsized uniformly distributed inclusions (Figure 4). This is due to the fact that chromium was introduced not in the form of elemental powder, but through chromium nitride, which is a stable chemical compound. Perhaps, the energy in the MA process is not enough for its decomposition with subsequent dissolution. A joint analysis of the XRD results and the distribution of alloying elements over the cross-section of particles (Figures $3 b, 4$ ) allow us to conclude that the intensity of the $\mathrm{CrN}$ peaks decreases not due to its dissolution in the iron lattice, but due to its grinding and volume distribution. According to the XRD patterns, after $30 \mathrm{ks}$ MA part of the CrN remains undissolved.
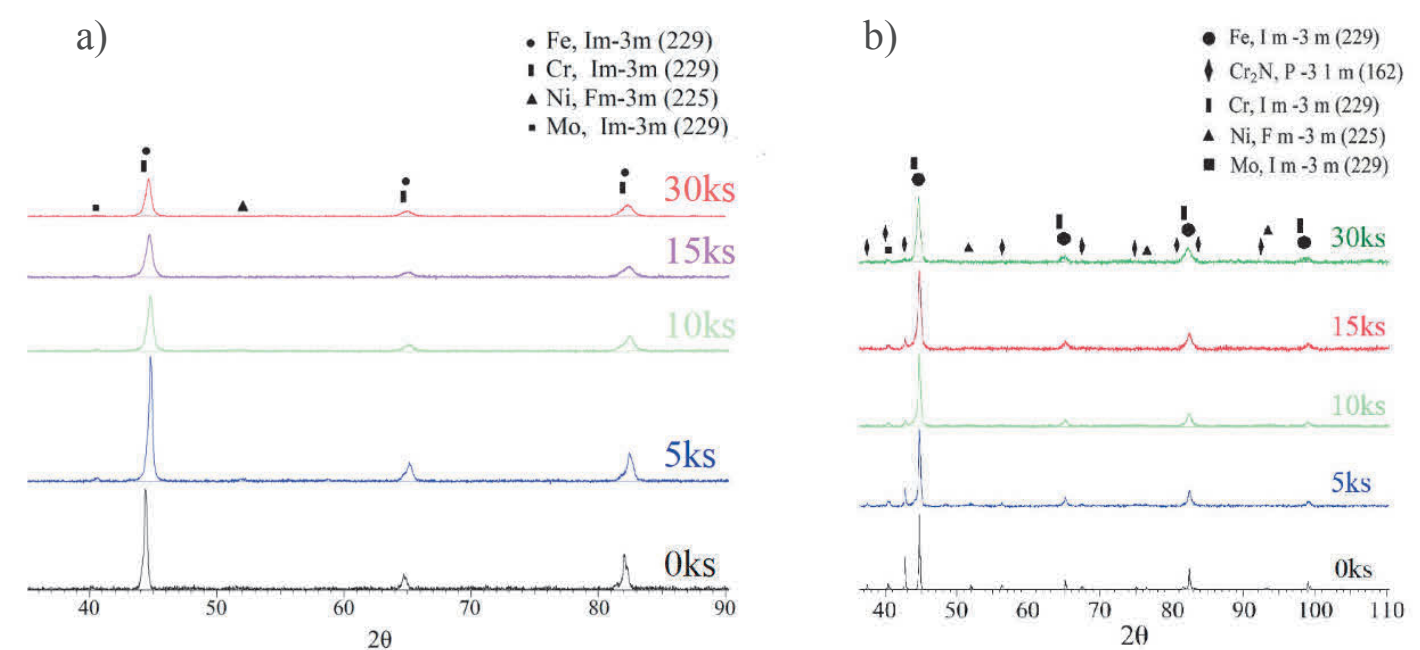

Figure 3 XRD results of Fe-Cr-Ni-Mn-Mo (a) and $\mathrm{Fe}_{-}-\mathrm{Cr}_{2} \mathrm{~N}-\mathrm{Ni}-\mathrm{Mn}-\mathrm{Mo}$ (b) composition powders obtained by $\mathrm{MA}$ at different milling times

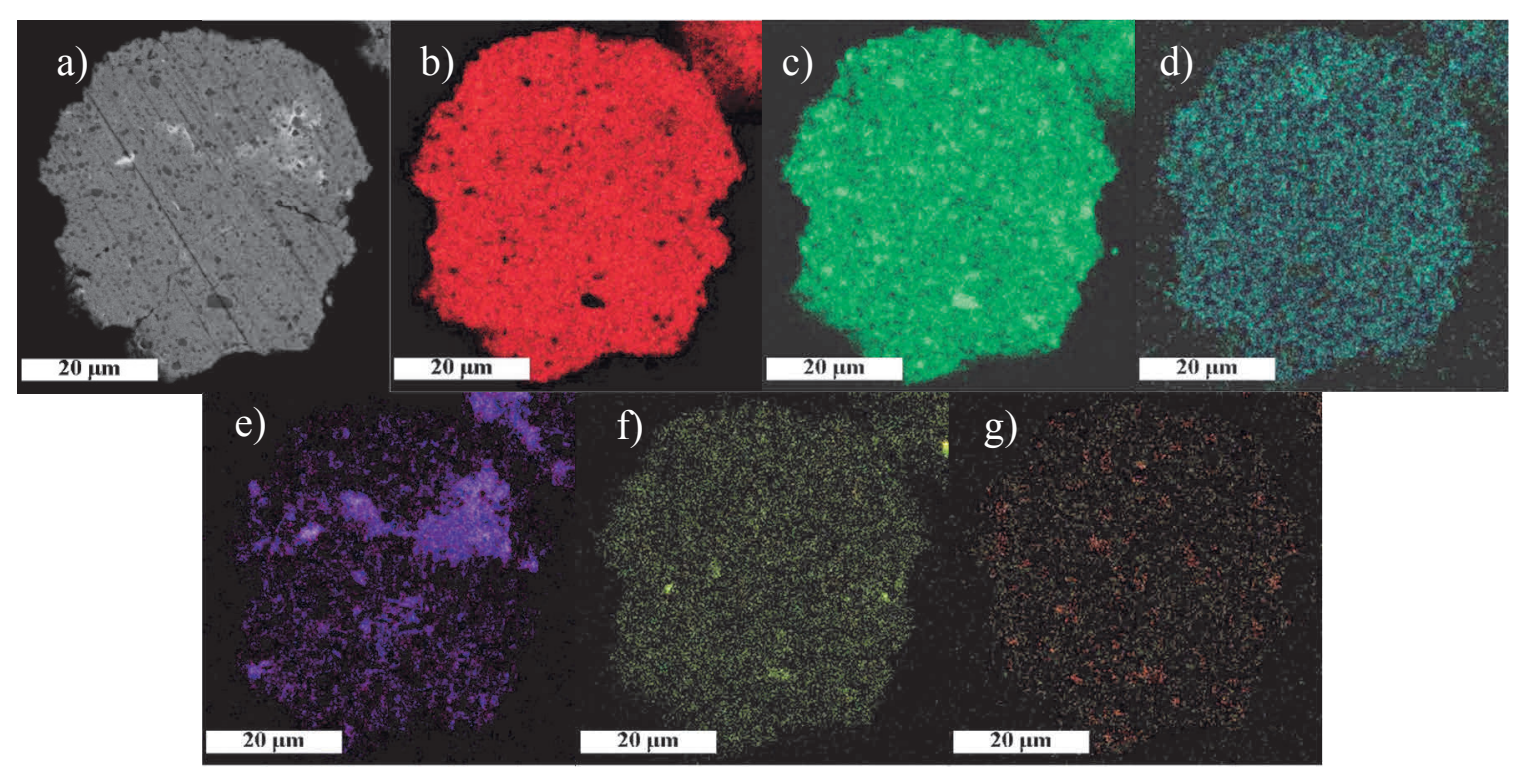

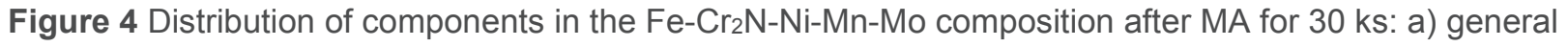
view; b) Fe; c) Cr; d) Ni; e) Mo; f) Mn; g) N

Chromium nitride and nitrogen-containing ferrochrome in the amount of $50 \%$ of the total chromium content almost completely dissolved in the iron lattice, only single inclusions of submicron size are observed. This change in solubility can be tried to explain by the presence of pure chromium, which is easier to dissolve in 
the $\alpha-F e$ lattice while expanding it and creating additional defects in it. In addition, due to the high affinity for nitrogen, pure chromium pulls a portion of nitrogen from nitride, accelerating nitrides decomposition and nitrogen diffusion into the lattice. Chemical analysis of samples thin sections for different compositions after $30 \mathrm{ks}$ MA showed that the average value of the alloying elements distribution in the particle volume is close to the chemical composition of the given powder composition (Table 1).

Table 1 Chemical composition of the Fe-16Cr-2.2Ni-0.6Mn-1.1Mo alloy, obtained by MA for $30 \mathrm{ks}$.

\begin{tabular}{|c|c|c|c|c|c|c|c|}
\hline \multirow{2}{*}{ Compositions } & \multicolumn{7}{|c|}{ Content of elements, wt\% } \\
\cline { 2 - 9 } & Fe & $\mathbf{C r}$ & $\mathbf{N i}$ & $\mathbf{M n}$ & Mo & $\mathbf{N}$ & $\mathbf{C}$ \\
\hline Fe-Cr-Ni-Mn-Mo & base & 16.28 & 2.10 & 0.64 & 1.24 & 0.02 & 0.05 \\
\hline Fe-Cr2N-Ni-Mn-Mo & base & 15.92 & 2.26 & 0.59 & 1.29 & 1.90 & 0.15 \\
\hline Fe-Cr2N-Ni-Mn2N-Mo & base & 17.48 & 2.21 & 0.83 & 0.93 & 1.70 & 0.10 \\
\hline Fe-Cr-Ni-FeMn-Mo & base & 15.63 & 2.84 & 1.03 & 0.85 & 0.04 & 0.09 \\
\hline Fe-FeCr-Ni-Mn-Mo & base & 15.59 & 2.37 & 0.65 & 1.13 & 3.61 & 0.06 \\
\hline Fe-0.5Cr-0.5Cr2N-Ni-Mn-Mo & base & 16.15 & 0.91 & 0.82 & 0.91 & 1.08 & 0.12 \\
\hline Fe-0.5Cr-0.5FeCr-Ni-Mn-Mo & base & 16.23 & 2.35 & 0.69 & 1.02 & 1.82 & 0.05 \\
\hline
\end{tabular}

Analysis of the nitrogen content showed that in the process of MA, up to $3.6 \%$ of nitrogen can be included into the alloy Fe-16Cr-2.2Ni-0.6Mn-1.1Mo, with an equilibrium content of $0.1 \%$ (Figure 5). Samples obtained using nitrogen-containing ferrochrome and chromium nitrides have the highest nitrogen content. The degree of nitrogen assimilation with this method of nitrogen doping is close to $95 \%$. According to the results of XRD analysis and SEM, most of the nitrogen is dissolved in the Fe lattice, but some of the nitrogen is in nitrides, which are uniformly distributed throughout the volume of particles in the form of submicron inclusions. It is assumed that the complete dissolution of the inclusions will occur in the process of powders plasma spheroidization.

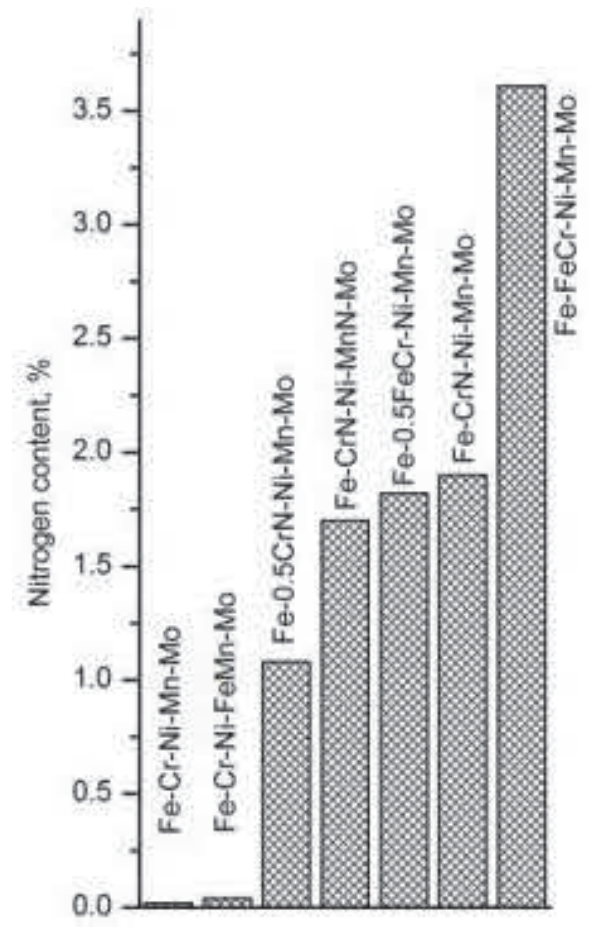

Figure 5 Nitrogen content in the Fe-16Cr-2.2Ni-0.6Mn-1.1Mo-N alloy after 30 ks MA 


\section{CONCLUSION}

In the present work, $16 \mathrm{Cr}-2 \mathrm{Ni}-\mathrm{Mn}-\mathrm{Mo}-\mathrm{xN}$ (wt\%) stainless steel powders were synthesized by mechanical alloying using nitrides and nitrogen-containing ferroalloy as a nitrogen source.

In the initial Fe-Cr-Ni-Mn-Mo system and in the Fe-Cr-Ni-FeMn-Mo system, where nitrogen-containing ferromanganese was used as the nitrogen source, after $30 \mathrm{ks}$ MA alloying elements are uniformly distributed throughout the powders and correspond to the initial chemical composition. In systems with a source of nitrogen in the form of chromium nitride and nitrogen-containing ferrochrome (contains the CrN phase and some $\mathrm{Cr}_{2} \mathrm{~N}$ ), the dissolution of alloying elements is worse than in the initial composition. Chromium nitride and nitrogen-containing ferrochrome in the amount of $50 \%$ of the total chromium content almost completely dissolved in the iron lattice, only single inclusions of submicron size are observed.

Samples obtained using nitrogen-containing ferrochrome and chromium nitrides have the highest nitrogen content (up to $3.6 \%$ of nitrogen can be included into the Fe-16Cr-2.2Ni-0.6Mn-1.1Mo alloy).

\section{ACKNOWLEDGEMENTS}

This research was supported by Russian Science Foundation grant (project № 18-73-00191).

\section{REFERENCES}

[1] GROMOV, V.I., VOZNESENSKAYA N.M., POKROVSKAYA N.G. and TONYSHEVA O.A. High-strength structural and corrosion-resistant steel FSUE "VIAM" for products of aviation equipment. Aviation materials and technologies. 2017. no. S, pp. 159-174.

[2] TONYSHEVA, O.A. and VOZNESENSKAYA, N.M. Prospective high-strength corrosion-resistant nitrogen-alloyed steel (comparative analysis). Aviation materials and technologies. 2014. vol. 32, no. 3, pp. 27-32.

[3] TONYSHEVA, O.A., VOZNESENSKAYA, N.M., ELISEEV, E.A. and SHALKEVICH A.B. Research of new highstrength economically alloyed nitrogen-containing steel of high reliability. Bulletin of Moscow State Technical University. N.E. Bauman. Series: Mechanical Engineering. 2011. no. SP2, pp. 131-136.

[4] WENG, Y., DONG, H. and GAN, Y. Advanced Steels. 2nd ed. Berlin: Heidelberg: Springer, 2011. p. 511.

[5] KOSTINA, M.V., BANNYKH, O.A. and BLINOV, V.M. Features of steel alloyed with nitrogen. Metal Science and Heat Treatments. 2000. No. 12. pp. 3-6.

[6] BLINOV, V.M, ELISTRATOV, V.M and KOLESNIKOV, A.G. Influence of heat treatment on structural transformations and properties of high-nitrogen steels. Metal Science and Heat Treatments. 2000. no. 6. pp. 1924.

[7] LI, Y. and KHOR, K.A. A Study of Processing Parameters in Thermal-Sprayed Alumina and Zircon Mixtures, J. Therm. Spray Technol. 2002. vol. 22, no. 8, pp. 186-194.

[8] RAZUMOV, N.G., POPOVICH, A.A. and WANG, Q.-S. Thermal Plasma Spheroidization of High-Nitrogen Stainless Steel Powder Alloys Synthesized by Mechanical Alloying. Metals and Materials International. 2018. vol. 24, no. (2, pp. 363-370.

[9] SIMMONS, J. W., KEMP, W. E. and DUNNING, J. S. The P/M Processing of High-Nitrogen Stainless Steels. Journal of Materials Science. 1996. vol. 48, no. 4, pp 20-23.

[10] POPOVICH, A.A. and RAZUMOV, N.G. Dissolution of alloying elements and phase formation in powder materials Fe-18Cr-8Ni-12Mn-xN during mechanical alloying. Advanced Materials Letters. 2014. vol. 5, no. 12, pp. 683 687. 